\title{
El fin de la adolescencia. Love \& Pop: recursos narrativos y cinematográficos en la adaptación audiovisual del discurso literario
}

\author{
The end of adolescence. Love \& Pop: \\ narrative and cinematographic sources \\ in the audiovisual adaptation of the literary discourse
}

\author{
MELANIE RUYBAL \\ UADE, Universidad Argentina de la Empresa; \\ ISEC, Instituto Sudamericano para la Enseñanza de la Comunicación \\ melanieruybal@gmail.com
}

Resumen: El nombre de Hideaki Anno suele asociarse al mundo del anime por su incursión en el género como creador de la serie Neon Genesis Evangelion, pero sin duda el rol al que debe vincularse dicho nombre es al de director audiovisual. La finalidad de este artículo es la de analizar los recursos narrativos y fílmicos adoptados por el director en Love \& Pop, su ópera prima de imagen real, filmada en 1998 y basada en la novela Topaz II del escritor Ryū Murakami. Se plantea como objetivo identificar las habilidades y herramientas cinematográficas que le permiten al realizador adaptar al lenguaje audiovisual temáticas como la adolescencia, los vínculos sociales y la prostitución.

Palabras clave: Cine, Literatura, Japón, Hideaki Anno, Enjo kōsai, adolescencia.

\begin{abstract}
Hideaki Anno's name is usually associated to the world of Japanese animation because of his work as the creator of Neon Genesis Evangelion. Although, the role this name should be linked is filmmaker. The purpose of his paper is analyze the narrative and cinematographic sources the director employs on his first live action film Love \& Pop, shot in 1998 and based in the novel Topaz II by the Japanese writer Ryū Murakami. Is set as an aim to identify the abilities and cinematographic resource that make the director able to adapt to the audiovisual language topics as adolescence, social relationships and prostitution.
\end{abstract}

Key Words: Cinema, Literature, Japan, Hideaki Anno, Enjo kōsai, Adolescence. 


\section{INTRODUCCIÓN}

El recorrido habitual que se hace al leer o escuchar el nombre del director japonés Hideaki Anno conduce a asociarlo, principalmente, a conceptos vinculados con el cine de animación japonés, es decir, con el anime. Conocido en sus inicios por ser discípulo de Hayao Miyazaki y por participar en la realización de cortos independientes como los que componen la saga Daicon, este animador obtuvo su máximo reconocimiento al crear y dirigir la saga animada Neon Genesis Evangelion (1995), producida por Gainax, estudio del que fue miembro fundador.

Anno logró distinguirse en la industria de la animación por dominar de manera particular dos factores fundamentales que exceden a la calidad del diseño de personajes: las temáticas que aborda y la narrativa que ejerce para hacerlo. Recorriendo siempre ejes vinculados a la exploración psicológica de personalidades con estereotipos conflictivos, el director logró atraer a un público que, envuelto en una forma de relatar donde predomina la ruptura de lo convencional, se arraigó a sus obras a través de un vulnerable proceso catártico de identificación.

Tomando como base este antecedente, en cuanto al desarrollo profesional del director y a sus inquietudes temáticas, en su mayoría relacionadas con la adolescencia, el entramado de los vínculos sociales y el análisis de la psiquis humana, no resulta sorprendente que, ante la propuesta de filmar su ópera prima de imagen real, Anno seleccionara, de entre un gran abanico de novelas candidatas para ser adaptadas a la pantalla grande, Topaz II de Ryū Murakami. La novela es la secuela de Topaz, del mismo autor literario, que fue previamente llevada a la pantalla grande bajo el nombre de Tokyo Decadence (1992), con la dirección del propio Murakami. El guion, adaptado por el mismo autor de la novela, recorre, de manera cercana a la versión literaria, la historia de Hiromi y sus tres amigas, un grupo de adolescentes en su último año de preparatoria, que, a simple vista, encajan con los arquetipos estereotipados de las estudiantes japonesas, pequeñas y jocosas, que siempre visten su aniñado uniforme escolar. Aun así, estas amigas rompen con la estructura inocente, típica y predecible, propia del género, que por costumbre envuelve a este tipo de personajes. En este caso, las jovencitas combinan el desarrollo de su amistad y la consolidación de memorias escolares utilizando la cámara fotográfica instantánea de la protagonista, con la práctica del enjo kösai.

El término enjo kōsai se refiere, en cuanto a su definición formal, a relaciones basadas en beneficios mutuos, asociándose a la práctica de vínculos que giran alrededor de la prostitución. Recientemente se utilizó para designar las relaciones en las que estudiantes de preparatoria salen o mantienen vínculos sexuales con hombres adultos a cambio de dinero u obsequios (Fukutomi, 
1997: 4). El origen exacto del enjo kōsai es difícil de definir, pero los medios comenzaron a cubrirlo entre principios y mediados de los 90 (McLellan, 2013: 28). El interés comunicacional alrededor de este fenómeno aparece no solo por la masificación de los medios, sino también por la acumulación de facilidades que las jóvenes en edad escolar encontraron para ejercerlo. Aunque el enjo kōsai ubica sus primeras manifestaciones a finales de los 70, las condiciones para propagar el ejercicio de estas prácticas se colmaron de facilidades tecnológicas en la década de 1990. Internet, pero, principalmente para dicha época, el contacto por medio de líneas telefónicas con una finalidad vinculada directamente con las citas a cambio de compensaciones, facilitó el contacto entre clientes y adolescentes en búsqueda de dinero rápido para satisfacer necesidades asociadas a adquirir cierto estatus entre sus pares.

En este contexto, con la constitución de todo un mundo social a representar basado en dichos hechos, Anno acepta el desafío de trasladar al soporte audiovisual un relato realista y por momentos crudo que afecta a la sociedad japonesa, con la correspondiente responsabilidad que implica dotarlo, a través de la imagen y el sonido, de la consistencia y espesor necesarios.

\section{ANÁLISIS DE LA ADAPTACIÓN: LOS PROCEDIMIENTOS FÍLMICOS}

El principal objetivo de cualquier proyecto audiovisual es conseguir los efectos comunicativos que dan origen a su puesta en marcha efectiva (Fernández Díez y Martínez Abadía, 1999: 15). Partiendo de esta premisa, emprendo el estudio según los principios de Casetti y Di Chio (2014) para el análisis de la representación fílmica, planeando como objetivo identificar las habilidades y recursos cinematográficos que le permiten al realizador adaptar al lenguaje audiovisual las temáticas mencionadas.

\subsection{La factura técnica}

El primer elemento no convencional de esta cinta aparece ante la elección de uno de los rasgos primordiales en lo que a factura técnica se refiere: durante el mes y medio que tomó filmar la película en localizaciones tanto en Tokio como en la isla de Okinawa, el director seleccionó para rodar una cámara digital hogareña.

La intención de esta elección, a la que se suma la definición de la resolución 4:3, propia de la televisión y no del cine, como formato de pantalla, determina la búsqueda de generar, dentro de la estructura del drama, códigos estéticos que remiten a grabaciones caseras, desde la visual de la protagonista, con ciertas referencias que pueden asociarse al cine documental. 


\subsection{La puesta en escena}

Partiendo de una propuesta que, en lo que se refiere a la puesta en escena, remite a buscar el efecto de un realismo fragmentado dentro del verosímil de la ficción, cobra coherencia que dicha búsqueda también quede evidenciada en la disposición de los informantes, es decir, en aquellos elementos del relato que se definen por su literalidad. En esta película no hay secretos para con el espectador. No solo no se ocultan factores elementales y comúnmente dados, como edades o géneros de los personajes, sino que también se exponen de manera clara sus cualidades y acciones, pudiéndose prescindir de indicios al estar ya todo dado desde el inicio. Solo queda, en base a lo planteado, esperar lo obvio dentro de un clima de tensión constante.

Love \& Pop, como texto fílmico, no busca generar un ejercicio de especulación sobre el espectador donde este deba jugar a deducir el desarrollo de acontecimientos futuros, sino que propone convertirlo en un compañero más de sus personajes a lo largo del lógico, sucesivo y casi predecible desarrollo de sus secuencias, que nunca dejan de incomodar. Trasladar la gramática del lenguaje escrito empleado en la literatura, soporte original de esta historia, al lenguaje cinematográfico, no es algo factible. Esto se debe a que ambas prácticas poseen estructuras diferentes. El cine, aunque agrupa sus unidades narrativas de menor a mayor, empleando un recorrido entre planos, escenas y secuencias que componen la totalidad de un filme, no tiene reglas de articulación semiológicas dadas de base, como sí las tiene la articulación del lenguaje literario, en el que el texto recreado en Love \& Pop fue concebido. El cine construye sus reglas y convenciones en la práctica, generando antecedentes que sirven de base y código para producciones futuras que en su conjunto afianzan géneros fílmicos.

Sustentándose en ese punto de vista, es posible justificar que, a pesar de estar trabajando con imagen real, el realizador recupere su herencia como director de animación, trayendo al desarrollo de este filme códigos y convenciones propias del anime en general y propias de su actividad sobre ese tipo de textos, como las presentes en alguno de sus trabajos previos, especialmente en la película animada The End of Evangelion. Anno juega con motivos que no solo son directrices funcionales al mundo representado en la película, sino que más bien lo son a su universo cinematográfico en general. El director resignifica para la ocasión, a lo largo del texto, ciertas unidades de contenido comunes en sus obras en función de reforzar la trama principal.

\subsection{El interior del cuadro}

Habiendo detallado los elementos esenciales de esta puesta en escena, es pertinente adentrarse en el análisis de factores específicos de la puesta 
en cuadro. El realizador, fiel a su estilo y recurriendo a recursos y convenciones que obligan al espectador a sentirse inmerso en el relato y en las sensaciones que genera, utiliza, para definir su mirada sobre el mundo que está representando con una modalidad variable, la heterogeneidad de las tomas. Aun así, articular todos estos criterios coherentes propios del discurso cinematográfico, con reglas expresivas vinculadas al discurso del anime, puede generar choques narrativos.

La elección de los planos presenta una reminiscencia que puede asociarse, principalmente desde su funcionalidad y duración, con aquellos a los que el cineasta ya ha recurrido en sus producciones animadas. Predominan los planos cortos y de detalle, con contrapuntos entre unos y otros a gran velocidad, principalmente en escenas donde se pretende transmitir la sensación de acoso que experimentan ciertos personajes que refuerzan la acción con movimientos corporales veloces y erráticos, marcados por el director y propios de la comicidad del texto animado. Bajo esta misma convención se detectan planos y contraplanos con juegos de angulaciones entre picado y contrapicado, que, como es de esperarse, indican niveles de autoridad.

Se efectúan planos generales de localización, cuyas duraciones trascienden lo habitual para el cine de imagen real, recurso que no genera interferencias en el discurso del anime pero que sí permite esbozar cierta lentitud en el plano del live-action, convirtiéndose en un sello de Anno, más que en una necesidad de localización espacio-temporal.

Dichos planos son un buen ejemplo de cómo el director abusa de manera confusa de la incorporación de un ojo de pez a la lente de su cámara, recurso aplicado de manera recurrente, tanto sobre planos cortos como sobre planos generales. Aparecen situaciones o presencias emblemáticas: planos generales de trenes y edificios, de cables y escaleras, de pasillos y columnas de iluminación en las calles; tomas con angulación supina de personajes flotando en el agua a contraluz o, por el contrario, cenitales desde la mirada de los personajes; composiciones simétricas con reminiscencias y funcionalidades pictóricas más que narrativas que embellecen a la imagen. Todos se hacen presentes con frecuencia para subrayar y cargar de sustancia a ciertos conceptos claves con una gran línea referencial a sus trabajos animados.

Anno hace uso y abuso de la cámara subjetiva en múltiples oportunidades, generando planos y angulaciones inusuales, entre los que destacan los planos aberrantes como una constante en todos sus trabajos, incluso inversiones totales de eje.

En primera instancia, Hiromi introduce la trama a través de la narración en off; con este objetivo, el director sitúa el punto de vista en la cámara fotográfica de dicho personaje. De este modo convierte a la cámara, de manera fluctuante, en un narrador anónimo de los hechos. 
Luego, el recurso se vuelve no solo recurrente, por presentar tomas subjetivas desde la mirada de todos los personajes, más allá de su rol en la cinta, sino también grotesco. Esto queda evidenciado cuando hace hincapié, desde la visual de los personajes, en planos cortos o planos de detalle de elementos que puedan generar cierta incomodidad en el espectador como la comida, los fluidos o determinados contrapuntos entre personajes en momentos de gran dramatismo. De ese modo, se busca asociar las sensaciones que estos conjuntos de planos provocan con las características tanto de los personajes como de las situaciones que el director plasma e intenta reflejar. También se hace uso de este recurso, tanto al inicio como al final de la película, al centrar la mirada desde el punto de vista de un tren de juguete que, avanzando y retrocediendo en un riel, efectúa varios travellings a modo de metáfora del camino narrativo que implica el recorrido de los personajes a través del desarrollo lineal de la historia. La puesta en práctica de dicho movimiento, en cuanto a su aplicación técnica, continúa efectuándose de un modo inusual, pues nunca se realiza con un carro de travelling profesional, pero sí por medio del tren de juguete en ese caso, y también montando la cámara en vehículos motorizados como camionetas ante la necesidad de hacer este tipo de movimientos de cámara a escala.

Probablemente esto sea parte de una elección estética y no resultado de una restricción presupuestaria. Esto puede concluirse al analizar la preferencia del director por los planos que presentan constantes movimientos inestables, situación que queda ejemplificada en las seguidillas a ciertos personajes bajo la modalidad de cámara en mano. El camarógrafo y su steadycam corren, a la par que avanza el desplazamiento de los personajes, principalmente ejecutando travellings circulares alrededor de estos, tanto cuando las protagonistas son abordadas por sus clientes, como cuando ellas se replantean de manera interna sus elecciones, reflejando de manera efectiva en la imagen el caos de una adolescencia sobrecargada con la práctica del enjo kōsai.

El realizador también espía a sus personajes, y con él lo hacen los espectadores, a través de objetos dentro de los que ubica a la cámara. Predominan planos cortos desde el interior de hornos, congeladores, fondos de vasos cuyo líquido ingresa en la boca de algún personaje, las profundidades de un anillo que se convierte en el objeto de deseo de la protagonista o incluso desde el interior de un televisor, en el que se yuxtapone lo que su pantalla proyecta con lo que sucede en el espacio en el que recibe su transmisión.

\subsection{Construcción del sentido: puesta en serie}

$\mathrm{Al}$ ingresar en aspectos vinculados a la puesta en serie, lo cual implica adentrarse en el montaje del filme e indagar en la forma en la que el 
realizador efectúa las relaciones y nexos entre el material rodado, resulta prudente reconocer los tipos de acciones con las que Anno realiza el enlace sucesivo de imágenes.

Abundan, por lógica, las asociaciones por identidad, donde, por medio de acercamientos, se repiten motivos contenidos en un mismo cuadro para establecer relaciones. También encontramos asociaciones por proximidad, generadas con planos y contraplanos que en su complemento expresan el vínculo entre los elementos de la escena. Además, hallamos asociaciones por transitividad, por medio de la constante presencia de travellings que integran de manera efectiva el universo representado, en gran parte de la película articulados en planos secuencia donde el montaje al cuadro adquiere un rol fundamental. Aun así, el procedimiento más destacado, que se convierte en una marca propia del director, en función de representar el caos del universo particular que busca plasmar, es el de las asociaciones neutralizadas. Anno envuelve a la contigüidad de los elementos expuestos en serie temporal en fragmentos inconexos jugando a gusto con las yuxtaposiciones con elementos y conceptos aparentemente desligados de los conceptos y situaciones básicas que debe representar. Las yuxtaposiciones son un recurso habitual en los trabajos de Hideaki Anno. El director articula a la imagen en movimiento dentro de lo que Sergei Eisenstein (2003) definía como montaje ideológico. Combina planos aparentemente inconexos y superpuestos con modificaciones cromáticas expresadas a través de planos en negativo o con piezas de música clásica como parte de la banda de sonido y monólogos internos en off, apelando así, desde la simbología, a la generación de emociones.

Con esta misma función, este realizador también recurre, como ocurre de manera frecuente en sus series de animación, al uso de intertítulos, no solo para citar respuestas en el contrapunto de intercambios telefónicos entre las adolescentes y sus clientes no identificados, sino principalmente para introducir conceptos clave con cierto bagaje moral que se entrelazan dentro del montaje.

\subsection{La articulación del discurso}

Dejando de lado las diferencias gramaticales, la elaboración tanto de un discurso literario como la creación de uno audiovisual comparten características, principalmente en cuanto a sus objetivos. Roland Barthes (2008) definió a la literatura como un juego de desplazamiento del sentido. Dicha definición también se puede aplicar a la forma de filmar de Hideaki Anno, quien desde sus modos propone una forma alternativa y poco habitual de exponer su mundo de ideas a través de un trabajo consciente y artesanal sobre el lenguaje audiovisual.

Partiendo de esta vinculación entre ambas técnicas comunicacionales, es factible entender el discurso en común que ambos textos comunican, 
así como también sus diferencias particulares, a través de la identificación de lo que Oscar Steimberg (2005) definió como rasgos retóricos, temáticos y enunciativos del discurso. De este modo es posible no solo localizar los aspectos comunes entre ambos, sino también comprobar e identificar las formas en las que se lleva a cabo el traslado y adaptación del texto de un dispositivo al otro.

En cuanto a la retórica, en ambos discursos se hacen presentes, por lógica, descripciones luego devenidas en relatos al organizarse la sucesión y transformación de los acontecimientos en una relación de términos causales. El factor diferencial de la construcción en el lenguaje audiovisual queda evidenciado en cómo se plantean las argumentaciones que permiten inferir y concluir las ideas generales del mensaje del texto. Este mecanismo se produce mayoritariamente a través de figuraciones, es decir, por medio de la implementación de elementos inusuales que el director introduce en el filme, sustituyendo las formas habituales de narrar asociadas a este tipo de cintas a partir de una ruptura, de la utilización de un modo audiovisual de decir inhabitual, ya descrito en el análisis fílmico.

Como resultado elabora un texto que en cuanto a lo temático yuxtapone motivos, es decir, fragmentos estereotipados constituyentes del tema de la novela, con los propios del universo audiovisual del director. De este modo se obtiene un texto de carácter metatextual. Love \& Pop no solo habla de Topaz II, sino que habla de otros textos, los de Hideaki Anno.

De esta manera se construye una escena comunicacional que, aunque se espera que en producción esté dirigida a quienes hayan leído la novela, siendo sus lectores los enunciatarios, encuentra a su público empírico en los seguidores del director, con quienes se facilita una relación comunicacional simétrica.

\section{El RESULTADO FinAL}

Habiendo emprendido este análisis, se comprende cómo la totalidad de los recursos utilizados por Hideaki Anno responden no a funcionalidades específicamente exploradas y ejercidas por el realizador para cumplir con el objetivo estándar de trasladar de manera "fiel" los contenidos planteados en Topaz II, ahora devenida en Love \& Pop, al lenguaje audiovisual cinematográfico. Más bien, lo que el director hizo -y continúa haciendo en su cine de imagen real actual, que se puede definir en base a estos rasgos como cine de autor- es tomar aquellas herramientas, recursos, códigos y convenciones con los que creció trabajando en el ámbito del anime y aplicarlos a la imagen real sin cuestionamiento alguno. 
Anno narra desde el lenguaje del anime. Lo hace desde sus años como estudiante de animación en la Universidad de Osaka y lo sigue demostrando en producciones recientes como las películas de la saga Rebuild of Evangelion, estrenadas a partir de 2013.

No busca adoptar las reglas del cine de género ni continuar la herencia narrativa japonesa, sino que, con sus propios recursos, busca cumplir con la función de contar una historia cuyo tema es funcional a los de sus intereses y búsquedas habituales: vulnerabilidades humanas, miserias sociales y conflictos psicológicos. Procura lograr que el espectador, al igual que él, reflexione al respecto de dichos puntos.

Podría haberlo hecho a través de una animación o desde una historieta, pues lo esencial en la búsqueda del director es la construcción del sentido de ese mensaje, de acuerdo con su visión sobre el tema y en común con la mayoría de sus obras. En este caso, esa exploración le valió el premio como Mejor Director Nuevo en la edición de 1999 del Festival de cine de Yokohama por una cinta que más allá de sus singularidades narrativas, cumple de manera efectiva con el objetivo comunicacional de expresar la visión del director sobre el tema que narra.

\section{Bibliografía CITADA}

BARTHES, Roland (2008), El placer del texto. Lección inaugural, México, Siglo XXI.

Casetti, Francesco y Federico Di Chio (2014), Cómo analizar un film, Barcelona, Paidós.

Eisenstein, Sergei (2003), La forma del cine, México, Siglo XXI.

Fernández DíEZ, Federico y José Martínez Abadía (1999), Manual básico de lenguaje y narrativa audiovisual, Barcelona, Paidós.

Fukutomi, Mamoru (1997), An Analytical Study on the Causes of and Attitudes toward "Enjo Kōsai" among Female High School Students in Japan, Tokio, Asian Women's Fund.

MCLellan, Gerald (2013), «An Examination of the Causes and Consequences of Compensated Dating (Enjo-Kosai) in Contemporary Japanese Society», Journal of Human Environmental Studies, 6, págs. 25-37.

Steimberg, Oscar (2005), Semiótica de los medios masivos. El pasaje a los medios de los géneros populares, Buenos Aires, Atuel.

Fecha de recepción: 22/07/2019.

Fecha de aceptación: 12/09/2019. 